Superalloys 2012: $12^{\text {th }}$ International Symposium on Superalloys

\title{
DYNAMIC STRAIN AGING IN Ni BASE ALLOYS WITH DIFFERENT STACKING FAULT ENERGY
}

\author{
C.Y.Cui, C.G.Tian, Y.Z.Zhou, T.Jin and X.F.Sun
}

Superalloys Division, Institute of Metal Research, Chinese Academy of Sciences, 72 Wenhua Road, Shenyang, China 110016

Keywords: Ni-base alloy, microstructure, stacking fault energy, dynamic strain aging (DSA), stacking fault (SF)

\begin{abstract}
Cobalt in a 23wt.\% Cobalt containing Ni-base superalloy was systematically substituted for by $\mathrm{Ni}$ in order to investigate the effects of stacking fault energy (SFE) on dynamic strain aging. The results showed that adding Co had little effect on the phase constituents, but the SFE of $\gamma$ matrix decreased continuously with increasing Co content. Mechanical properties tests showed that all the alloys exhibited serrated flow during tensile deformation due to dynamic strain aging (DSA) within a temperature ranges of $200^{\circ} \mathrm{C}-500^{\circ} \mathrm{C}$. The starting temperature for serration improved from $200^{\circ} \mathrm{C}$ to $300^{\circ} \mathrm{C}$ with increasing the Co content from $5 \mathrm{wt} \%$ Co in Alloy1 to 23wt\% Co in Alloy3. In the serrated flow regime, all the alloys clearly exhibited the normal and inverse DSA behaviors. The tensile properties such as yield stress, ultimate tensile strength and fracture feature in DSA regime were not influenced by temperature, strain rate and Co content. A relation between high density of SF and the inverse DSA effect was found in Alloy3 with low stacking fault energy. Analysis of the results suggested that the mechanism for the inverse DSA is related to the locking of the mobile dislocation by substitutional elements.
\end{abstract}

\section{Introduction}

Serrated flow during plastic deformation is commonly observed in many alloys within a certain regime of temperature and strain rate. This serration in alloys, generally referred to as the Portevin-Le Chatelier (PLC) effect, is considered to be an instability associated with dynamic strain aging (DSA). The dynamic interaction between diffusing solute atoms and mobile dislocations during plastic flow is generally accepted to explain the observed phenomena [1].

Dynamic strain aging has also been observed in many nickel-base superalloys with different microstructures over a range of temperatures and strain rates [2-7]. For example, negative values of strain rate sensitivity and a PLC effect have been observed in aged Waspaloy [2, 3], Udimet720Li [4] and Inconel718 [5-7]. Normal behavior, i.e., critical strain for serration $\left(\varepsilon_{\mathrm{c}}\right)$ increases with decreasing test temperature and increasing the strain rate, is often observed in these Ni-base superalloys. However, in peak aged Waspaloy [2], Udimet720Li [4] and Inconel718 [7], the inverse behavior, i.e., $\varepsilon_{\mathrm{c}}$ increases with increasing temperature and decreasing strain rate, is also found. Hayes et al. [2, 3] attributes the diffusion of interstitial $\mathrm{C}$ atoms forming an atmosphere around mobile dislocations to be responsible for serrated yielding in Waspaloy. They further suggest that the change from normal to inverse behavior should be a result of interactions between carbon atmospheres and the $\gamma^{\prime}$ strengthening precipitates. Gopinath et al. [4] suggest that the locking of mobile dislocations by substitutional alloy elements (Cr, $\mathrm{Co}, \mathrm{Ti}, \mathrm{Al}$, Mo and $\mathrm{W}$ ) would be responsible for the DSA in Udimet720Li. Hale et al. [7] have identified that the lattice diffusion of interstitial $\mathrm{C}$ atoms at lower temperatures $\left(127-427^{\circ} \mathrm{C}\right.$ ) and of substitutional $\mathrm{Cr}$ atoms at higher temperatures $\left(477-627^{\circ} \mathrm{C}\right)$ is responsible for serrated yielding in Inconel 718.

From the brief literature reviews, the following points appear: (i) most of the studies explains the mechanisms for DSA on the basis of the activation energy for diffusion of different solutes in the serrated regime; (ii) at low temperature, the diffusion of $\mathrm{C}$ atom is responsible for the DSA, while at high temperature, there is different opinion as to which element is responsible for DSA.

Recently, Cui et al. [8], from TEM observations on the tensile deformed samples in the normal and inverse DSA regimes, suggest that the normal behavior should be associated with conventional DSA mechanism due to dynamic dislocation-solute interaction, while the inverse behavior would be related to the occurrence of stacking faults (SF) in a new Ni-Co base superalloy. Further study [9] on the heat treatment effects on DSA shows that the microstructural parameters, such as tertiary $\gamma^{\prime}$ fraction and size, have great effects on the evolution of SF. In these papers, high density of SFs is found not in the normal DSA regime, but in the inverse DSA, probably due to the low stacking energy in the Ni-Co based superalloys. It is noted that the Ni-Co base alloys contain high amounts of Co (>20wt\%). The element Co has been reported to have great effect on SFE in Ni-Co binary alloys $[10,11]$. Recently, Yuan et al [12] have reported that the SFE has nonlinear relationship against Co content of the $\gamma$ matrix and the lowest SFE could be attained at about 34at.\%Co in the matrix of TMW alloys.

Up to now, a systematic study on the effect of SFE on DSA has not been addressed in the literature. In this work, we focus on the effect of SFE on the DSA of the Ni base superalloy. The alloys with different SFE were designed by changing Co contents. We identify the serrated flow in three alloys with different Co contents and propose an explanation for the effect of SFE on the DSA.

Table 1 Nominal chemical composition of the Ni base superalloys with different Co contents (wt.\%).

\begin{tabular}{|c|c|c|c|c|c|c|c|c|c|c|c|}
\hline & $\mathrm{Cr}$ & $\mathrm{Co}$ & $\mathrm{Mo}$ & $\mathrm{W}$ & $\mathrm{Ti}$ & $\mathrm{Al}$ & $\mathrm{B}$ & $\mathrm{Zr}$ & $\mathrm{C}$ & $\mathrm{Ce}$ & $\mathrm{Ni}$ \\
\hline Alloy1 & 14 & 5 & 2.8 & 1.2 & 5.6 & 2.3 & 0.015 & 0.03 & 0.02 & 0.01 & Bal. \\
\hline Alloy2 & 14 & 15 & 2.8 & 1.2 & 5.6 & 2.3 & 0.015 & 0.03 & 0.02 & 0.01 & Bal. \\
\hline Alloy3 & 14 & 23 & 2.8 & 1.2 & 5.6 & 2.3 & 0.015 & 0.03 & 0.02 & 0.01 & Bal. \\
\hline
\end{tabular}



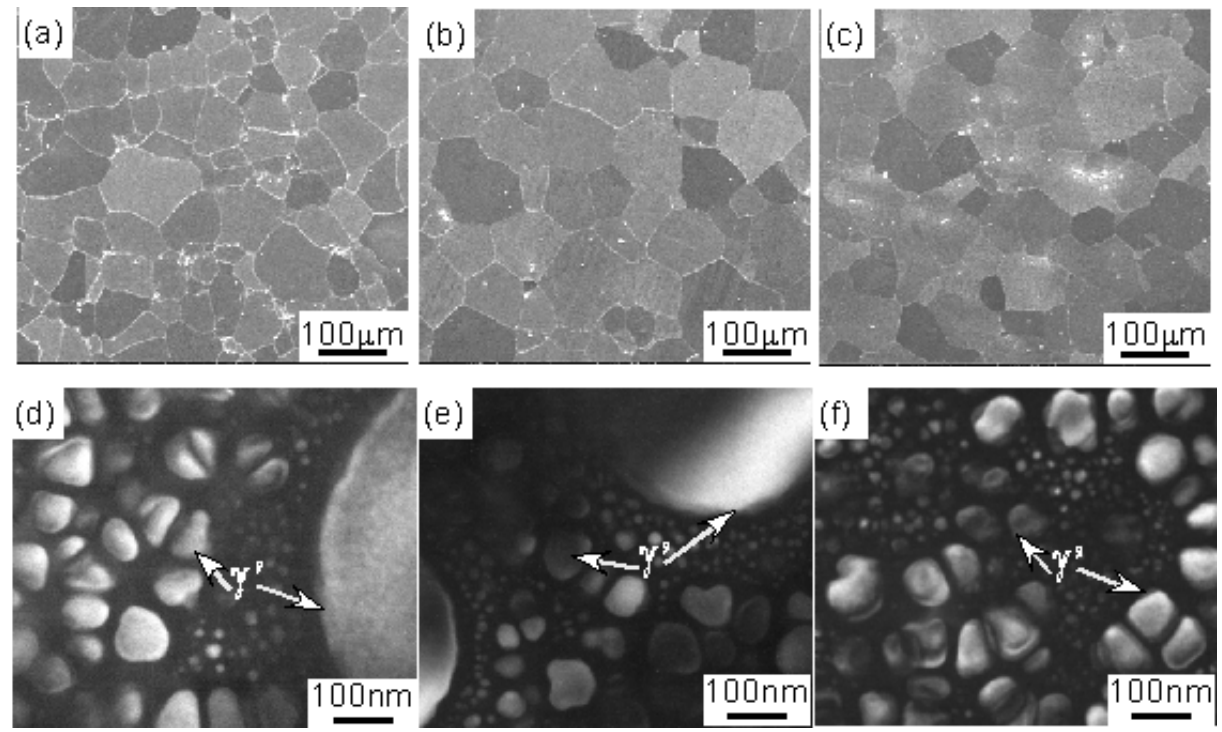

Figure 1 Typical microstructures of the Ni-base superalloys with different Co contents. (a) and (d) represent Alloy1, (b) and (e) represent Alloy2, and (c) and (f) represent Alloy3, respectively. (a) (c) shows SEM images, and (d) (f) shows TEM images.

\section{Experimental procedure}

The nominal composition of Ni-Co based superalloys is listed in Table 1. For all three alloys, 20-kg ingots were made using vacuum induction melting (VIM) followed by casting. These ingots were hot extruded into $\phi 30 \mathrm{~mm}$ billets with extrusion ratio of 6 at about $1140^{\circ} \mathrm{C}$. The extruded samples were heat-treated at $1100{ }^{\circ} \mathrm{C} / 4 \mathrm{~h}$ (air cooling) followed by aging at $650{ }^{\circ} \mathrm{C} / 24 \mathrm{~h}$ (air cooling) and $760{ }^{\circ} \mathrm{C} / 16 \mathrm{~h}$ (air cooling) as reported for U720Li alloys [13]. Samples for optical microscopy were prepared using conventional metallographic procedures and chemically etched by a Kalling solution. The TEM disks with thickness of about 300 $\mu \mathrm{m}$ were cut from the samples perpendicular to the tensile axis. Then the disks were manually ground down to $50 \mu \mathrm{m}$ and perforated by twin-jet electro-polisher at $40 \mathrm{~V}$ and $0{ }^{\circ} \mathrm{C}$. TEM observations were carried out on a TECNAI 20 TEM operated at $200 \mathrm{kV}$.

All tensile tests were performed on the specimens having a gage section of $\phi 3 \times 16 \mathrm{~mm}^{3}$. Tensile tests were performed on a Shimadz250KN machine at temperatures ranging from room temperature to $750{ }^{\circ} \mathrm{C}$ and initial strain rates ranging from $3 \times 10^{-3}$ $\mathrm{s}^{-1}$ to $8 \times 10^{-5} \mathrm{~s}^{-1}$, respectively. The shear modulus, $\mathrm{G}$ and the Poisson's ratio V were measured by a RFDA HTVP 1750-C machine by using dynamic measuring method according to ASTM E1876-09.

\section{Results}

\section{$\underline{\text { Microstructures }}$}

Figure 1 shows the heat-treated microstructures of Ni-base alloys with different Co contents. All the alloys had a homogeneous microstructure which implied that the solution treatment was performed fully for all the alloys. As shown in Fig.1(a)-(c), all the alloys mainly consisted of equiaxed $\gamma$ grain (about $30 \mu \mathrm{m}$ ) and small amounts of carbides at the grain boundaries. At high magnification (Fig.1(d)-(f)), the microstructures revealed a sparse distribution of secondary $\gamma^{\prime}$ precipitate with size varying between 50 and $150 \mathrm{~nm}$ and fine $\gamma^{\prime}$ precipitate (typically less than $30 \mathrm{~nm}$ and formed during aging or cooling from the aging treatment). The morphology and size of $\gamma^{\prime}$ precipitate were almost the same for all the alloys with different Co content. These results indicated that adding Co had little effect on the phase constituents. Qualitative metallurgy showed that the total $\gamma^{\prime}$ fraction was not affected by Co content. Co, however, did affect the fraction of different types of $\gamma^{\prime}$, as shown in Fig.1(d)- (f). The compositions of the secondary $\gamma^{\prime}$ were measured by TEM-EDS, as shown in Table II, which showed that the $\gamma^{\prime}$ phase existed as $(\mathrm{Ni}, \mathrm{Co})_{3}(\mathrm{Al}, \mathrm{Ti})$ in these three alloys. Adding Co was preferentially partial to the $\gamma$ phase and increasing Co in the Alloy 2 and Alloy 3 resulted in an increase of the Co contents in the $\gamma^{\prime}$ precipitate.

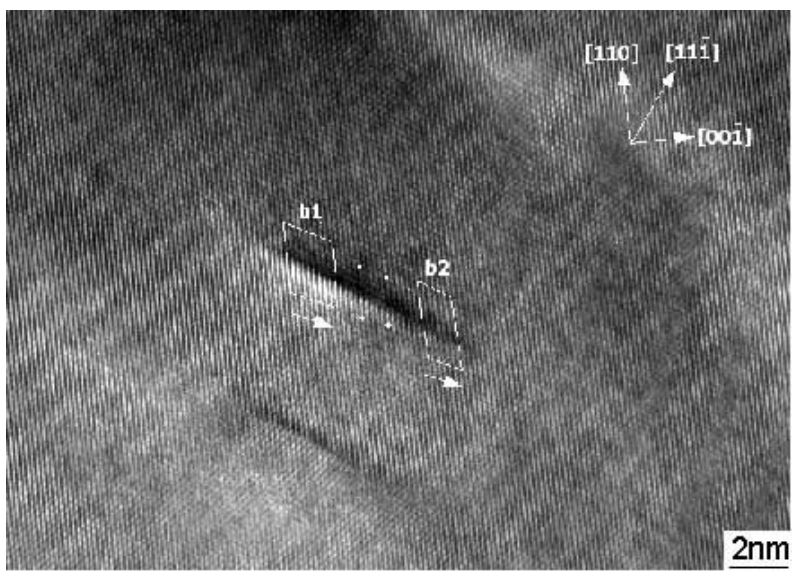

Figure 2 High resolution transmission electron microscopy (HRTEM) image showed an extended dislocation in Alloy 1. 
Table II The chemical composition of the $\gamma^{\prime}$ phase analyzed by TEM-EDS (wt.\%).

\begin{tabular}{|c|c|c|c|c|c|}
\hline & $\mathrm{Cr}$ & $\mathrm{Co}$ & $\mathrm{Ti}$ & $\mathrm{Al}$ & $\mathrm{Ni}$ \\
\hline Alloy1 & 2.8 & 2.9 & 11.5 & 6.4 & 72.4 \\
\hline Alloy2 & 3.2 & 9.4 & 12.2 & 4.2 & 70.8 \\
\hline Alloy3 & 3.7 & 15.7 & 12.5 & 4.2 & 63.1 \\
\hline
\end{tabular}

\section{$\underline{\text { SFE of the alloys }}$}

According to reference 12, the SFE can be calculated from the following equation:

$\gamma_{S F}=\frac{G b^{2} \cdot(2-v)}{8 \pi \cdot d \cdot(1-v)} \cdot\left(1-\frac{2 v \cdot \cos 2 \Phi}{2-v}\right)$

where $\gamma_{\mathrm{SF}}$ is the SFE, $G$ is the shear modulus, $v$ is the Poisson's ratio, $b$ is the Burgers vector of partial dislocation, $d$ is the separation width of two partials (SF width), $\Phi$ is the angle between line direction of the undissociated dislocation and the Burgers vector.

Here, the $G$ and $v$ were obtained by dynamic measuring method, and the values were given in Table III, $\mathrm{b}=0.15 \mathrm{~nm}$ (assuming lattice parameter of the alloys $a=0.36 \mathrm{~nm}$ ), $d$ was measured to be $5.2 \mathrm{~nm}$ from the dissociation of a perfect matrix dislocation with Burgers vector of $a / 2<110>$ in Alloy 1 , as shown in Figure 2. By substituting the corresponding values, the stacking fault energy in Alloy1 was calculated to be $41.3 \mathrm{~mJ} / \mathrm{m}^{2}$. In order to minimize the errors, another extended dislocation in different area was also measured. The average SFE of $\gamma$ matrix in Alloy 1 was measured to be $40.1 \pm 1.2 \mathrm{~mJ} / \mathrm{m}^{2}$. By using the same method, the average SFE of $\gamma$ matrix in Alloy2 and Alloy3 was calculated and listed in Table III. It is clear that the SFE decreased continuously with increasing Co content in the tested alloys.

Table III Parameters used for calculation and SFE in the tested alloys

\begin{tabular}{|c|c|c|c|c|c|}
\hline \multirow{2}{*}{ Alloy } & \multirow{2}{*}{$\mathrm{G}(\mathrm{GPa})$} & \multirow{2}{*}{$v$} & \multicolumn{2}{|c|}{ Stacking fault width } & \multirow{2}{*}{\begin{tabular}{r}
$\gamma_{\mathrm{SF}}$ \\
\cline { 4 - 5 }
\end{tabular}} \\
\cline { 4 - 5 } & & $\mathrm{d}_{1}{ }^{*}$ & $\mathrm{~d}_{2}{ }^{*}$ & \\
\hline Alloy1 & 86.4 & 0.28 & 3.2 & 5.2 & $40.1 \pm 1.2$ \\
\hline Alloy2 & 87.7 & 0.26 & 4.0 & 3.8 & $33.3 \pm 0.9$ \\
\hline Alloy3 & 89.6 & 0.23 & 5.6 & 8.2 & $24.9 \pm 0.5$ \\
\hline
\end{tabular}

$\mathrm{d}_{1}$ and $\mathrm{d}_{2}$ are the separation width of two partials in different area.

\section{Mechanical property testing}

\section{Tensile stress-strain curves}

Figure3 shows the typical true stress vs true strain curves obtained at a few temperatures at a strain rate of $3 \times 10^{-4} \mathrm{~s}^{-1}$. Serrated stress-strain curves were observed at the test temperatures ranging from $200^{\circ} \mathrm{C}$ to $500^{\circ} \mathrm{C}$, depending on the Co content in the alloys, that is, $200^{\circ} \mathrm{C}$ to $400^{\circ} \mathrm{C}$ in Alloy1, $250^{\circ} \mathrm{C}$ to $450^{\circ} \mathrm{C}$ in Alloy2 and $300^{\circ} \mathrm{C}$ to $500^{\circ} \mathrm{C}$ in Alloy3, respectively. The stress-strain curve at temperatures out of this range was smooth. There was a tendency that the starting and ending temperatures for serrations increased with increasing Co content. In addition, the elongation of all the alloys was about $15 \%$, independent of tested temperatures.
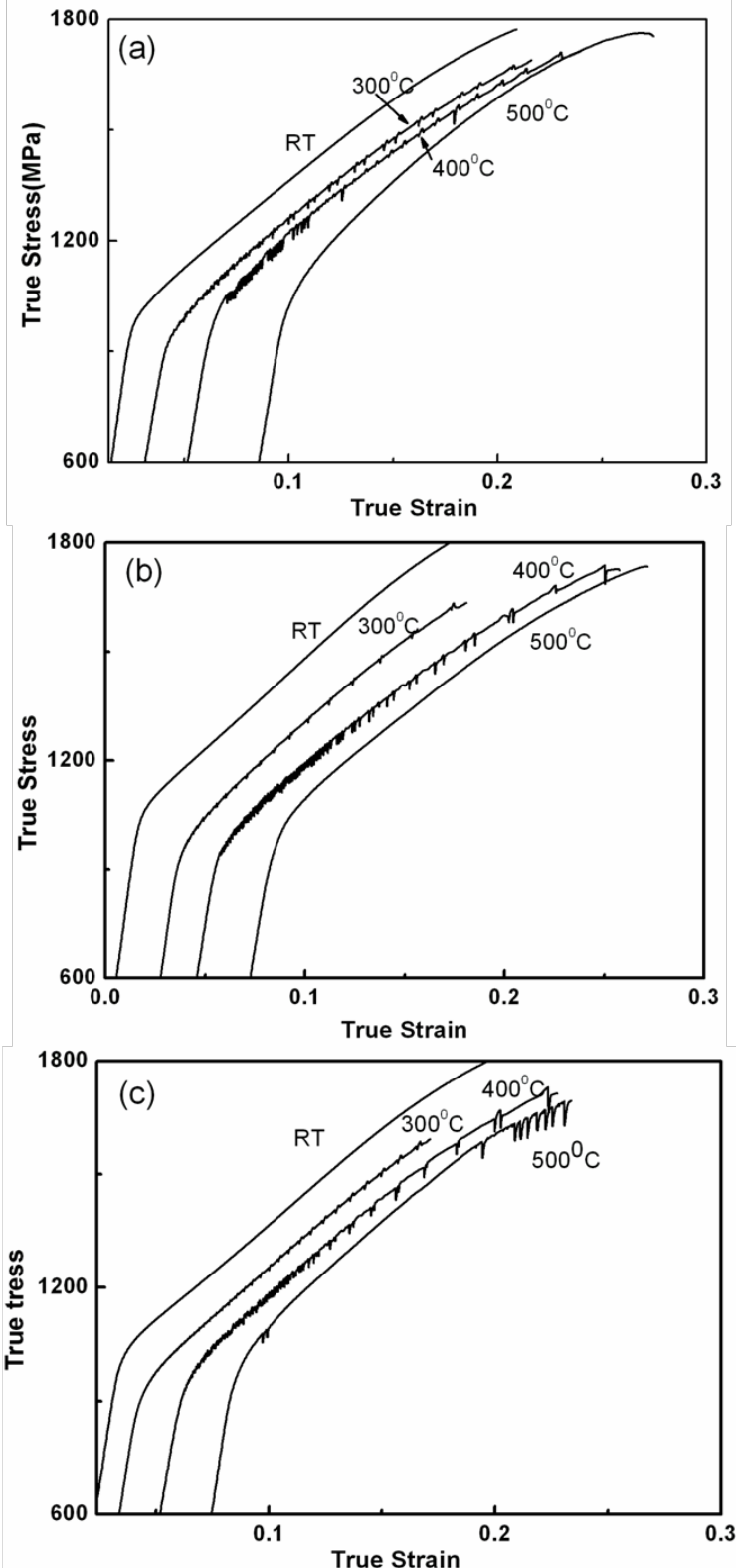

Figure 3 Typical true stress versus strain curves of (a) Alloy1, (b) Alloy2 and (c) Alloy3 obtained at a few temperatures at a strain rate of $3 \times 10^{-4} \mathrm{~s}^{-1}$. The curves are artificially offset from each other to help with visualization.

Figure 4 shows the typical true stress vs true strain curves obtained at $450{ }^{\circ} \mathrm{C}$ at strain rates ranging from $3 \times 10^{-3}$ to $8 \times 10^{-5} \mathrm{~s}^{-1}$. The serrated curves were clearly observed at high strain rates, and the serrations disappeared at low strain rate, for example, the tensile curve was smooth in the Alloy1 and Alloy2 tested at strain rate of $8 \times 10^{-5} \mathrm{~s}^{-1}$. In contrast, the serrated curves were observed in the Alloy3 with high Co content in the tested strain rate. Type A, $\mathrm{B}$, and $\mathrm{C}$ serrations were observed in the stress-strain curves. Specifically, Type A serrations were observed in all the tested alloys at lower temperatures. Type B serrations of very small 
magnitude could also be observed in the tested alloys, and it disappeared at higher strains. Type $\mathrm{C}$ serrations were easily observed in the Alloy3 within most of the temperatures and strain rates studied, i.e. $\mathrm{T} \geq 400^{\circ} \mathrm{C}$ and $\dot{\varepsilon} \leq 3 \times 10^{-3} \mathrm{~s}^{-1}$. Thus, Type C serrations easily occurred in the Alloy3 with low SFE.
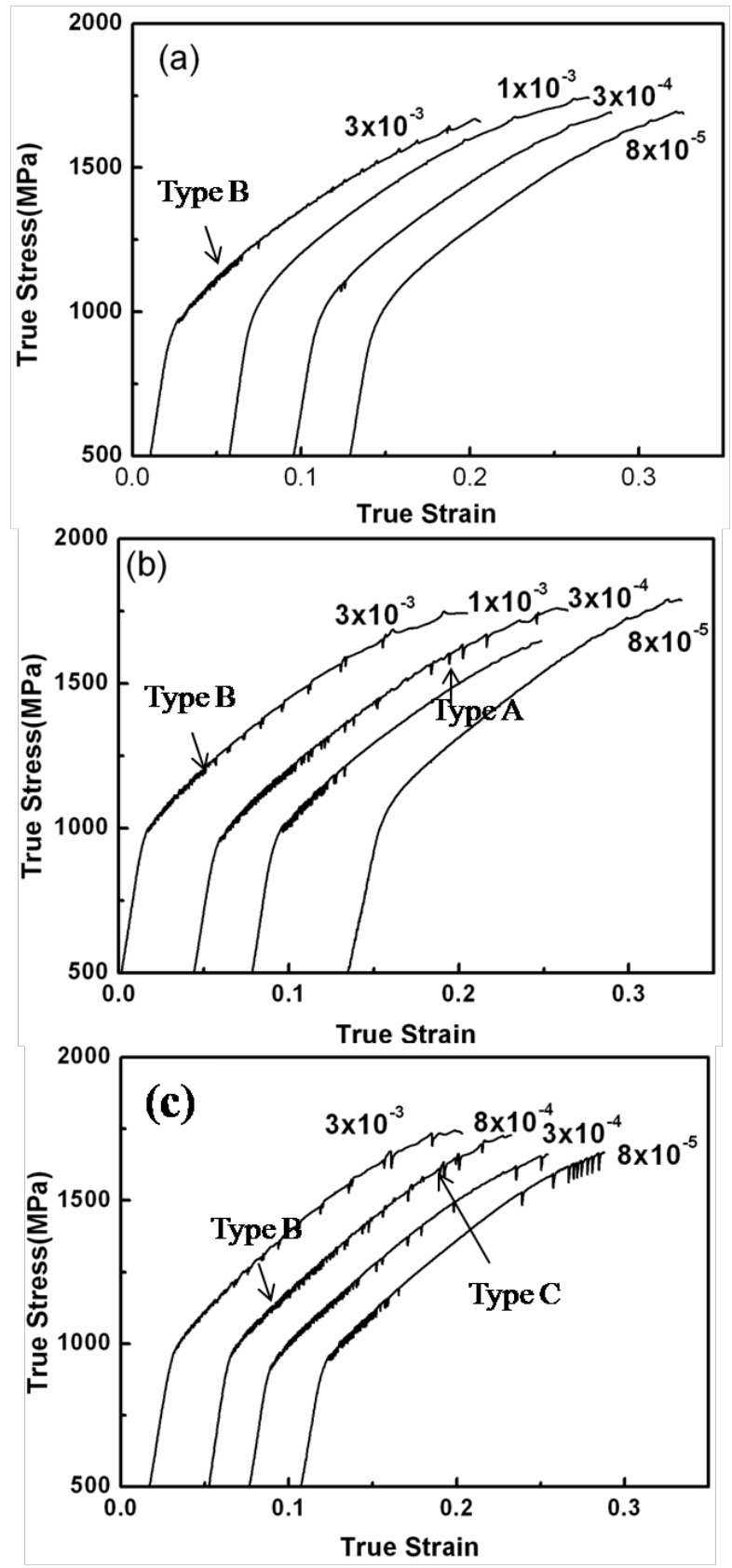

Figure 4 Typical true stress versus strain curves of (a) Alloy1, (b) Alloy2 and (c) Alloy3 obtained at $450^{\circ} \mathrm{C}$ at four different strain rates. The curves are artificially offset from each other to help with visualization.
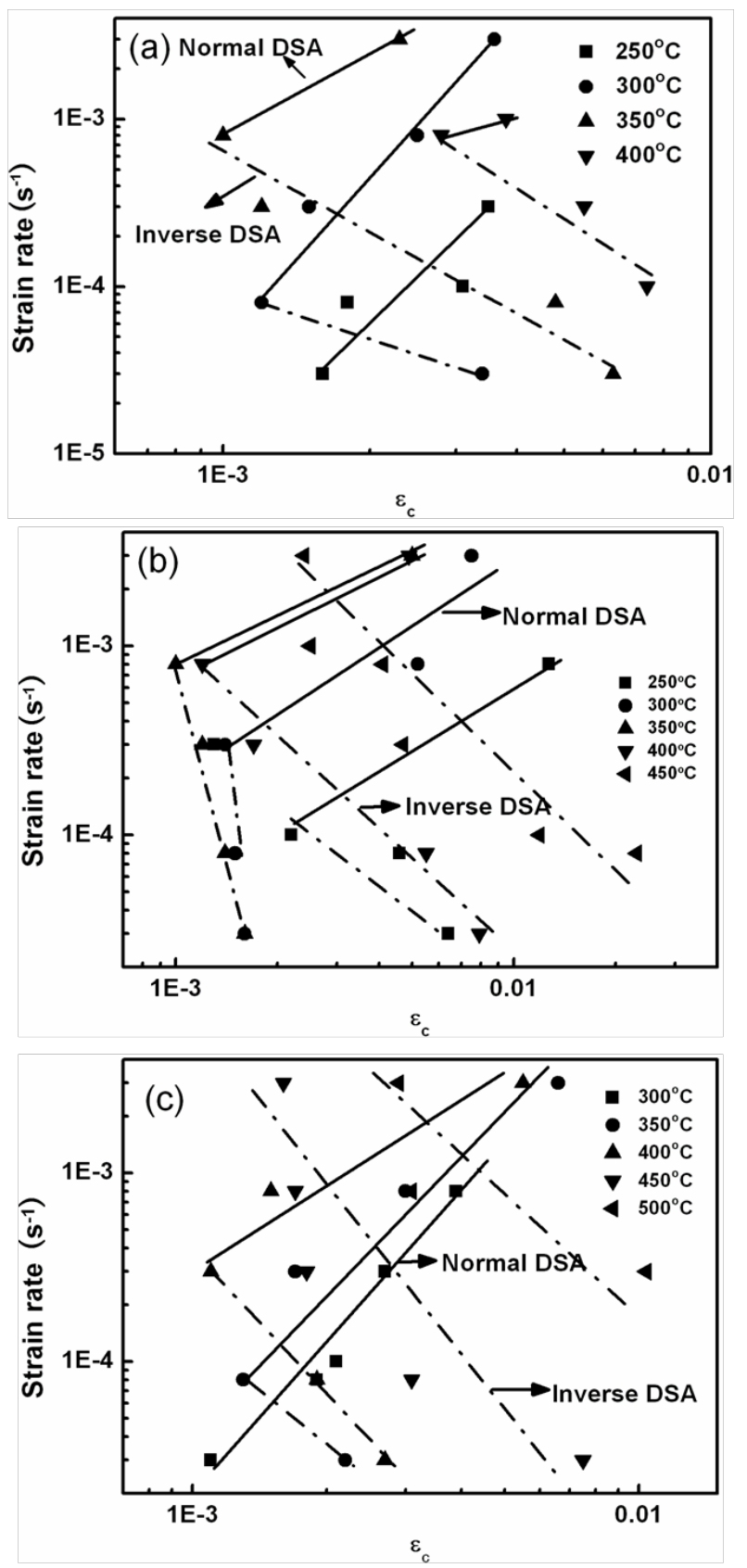

Figure 5 Variation of critical strain, $\varepsilon_{\mathrm{c}}$ for onset of serration with strain rate and temperature, (a) Alloy1, (b) Alloy2, and (c) Alloy3. The strait lines show the normal DSA, while the dash dot lines show the inverse DSA.

Serrated flow is generally seen to occur after a critical true plastic strain, $\varepsilon_{c}$, is reached as shown in Fig.3 and Fig.4. The strain corresponding to the peak of the first serrations was taken as the critical true plastic strain, $\varepsilon_{\mathrm{c}}$, for onset of serrations. $\varepsilon_{\mathrm{c}}$ ranged mainly between $0.1 \%$ and $3 \%$, depending on temperature and 
strain rate. Figure 5 shows the variation of $\varepsilon_{\mathrm{c}}$ with $\dot{\varepsilon}$ at various temperatures within the DSA regime. There were two trends in these figures: one was associated with increasing $\varepsilon_{\mathrm{c}}$ with increasing $\dot{\varepsilon}$ and decreasing T, which was called normal DSA. Another was associated with increasing $\varepsilon_{\mathrm{c}}$ with decreasing $\dot{\varepsilon}$ and increasing $\mathrm{T}$, which was called inverse DSA effect. The normal DSA effect was observed at high $\dot{\varepsilon}$ and/or low $\mathrm{T}$, while the inverse DSA effect was observed at high T and low $\dot{\varepsilon}$. All these three alloys exhibited normal and inverse DSA, independent of Co content.

The previous studies of serrated flow showed that the critical strain for the onset of serration and its dependence on strain rate and temperature is very important for understanding the DSA mechanism. This dependence can be expressed as [14]:

$$
\varepsilon_{c}^{m+\beta}=\mathrm{K} \dot{\mathcal{E}} \exp \left(Q_{m} / k T\right)
$$

where $m$ and $\beta$ are exponents in the relations for variation of vacancy concentration with strain and mobile dislocation density with strain, Q is the activation energy, R is the gas constant and $\mathrm{T}$ is the absolute temperature. The activation energy obtained by this method was listed in Table IV. It varied from 40 120 kJ/mol. All the three alloys had the similar activation energy in the normal regime, and they also had the similar activation energy in the inverse regime. However, the activation energy in the normal DSA regime was much lower than that in the inverse DSA regime, as reported in the references.

The variation of yield stress and ultimate tensile strength with temperature is given in Figure 6. The results indicated that the reduction of $\mathrm{Co}$ in the alloy has little effects on tensile properties. At room temperature, the yield stress was almost the same for all the alloys, and the tensile strength decreased slightly from 1820
MPa to $1770 \mathrm{MPa}$ as Co was reduced from 23wt\% to $5 \mathrm{wt} \%$. In addition, the yield stress of all the alloys was slightly affected by temperatures ranging from RT to $750^{\circ} \mathrm{C}$, while the UTS began decreasing gradually from $500^{\circ} \mathrm{C}$, and decreased markedly at temperature above $600^{\circ} \mathrm{C}$.

Table IV Temperature range of the serrated curve, serration type and activation energy of three alloys.

\begin{tabular}{|c|c|c|c|c|}
\hline & Temperature range & Serration type & $\mathrm{Q}(\mathrm{kJ} /$ & \\
\hline \multirow{2}{*}{ Alloy1 } & \multirow{2}{*}{$200 \sim 400{ }^{\circ} \mathrm{C}$} & \multirow[b]{2}{*}{ A, } & Normal & 44 \\
\hline & & & Inverse & 104 \\
\hline \multirow{2}{*}{ Alloy2 } & \multirow{2}{*}{$250 \sim 450$} & \multirow{2}{*}{ A, B, C } & Normal & 40 \\
\hline & & & Inverse & 113 \\
\hline \multirow{2}{*}{ Alloy3 } & \multirow{2}{*}{$300 \sim 500^{\circ} \mathrm{C}$} & \multirow{2}{*}{ A, B, } & Normal & 60 \\
\hline & & & Inverse & 105 \\
\hline
\end{tabular}

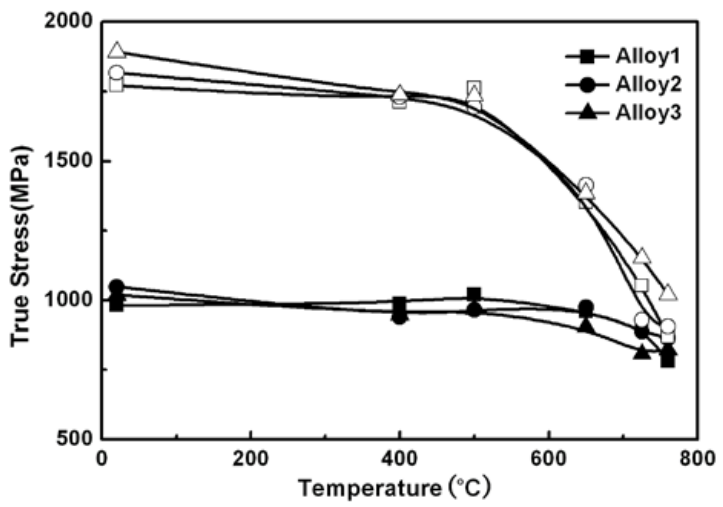

Figure 6 Variation of yield stress and ultimate tensile strength with temperature. The solid symbols represent the yield stress, and the open symbols represent the ultimate tensile strength.
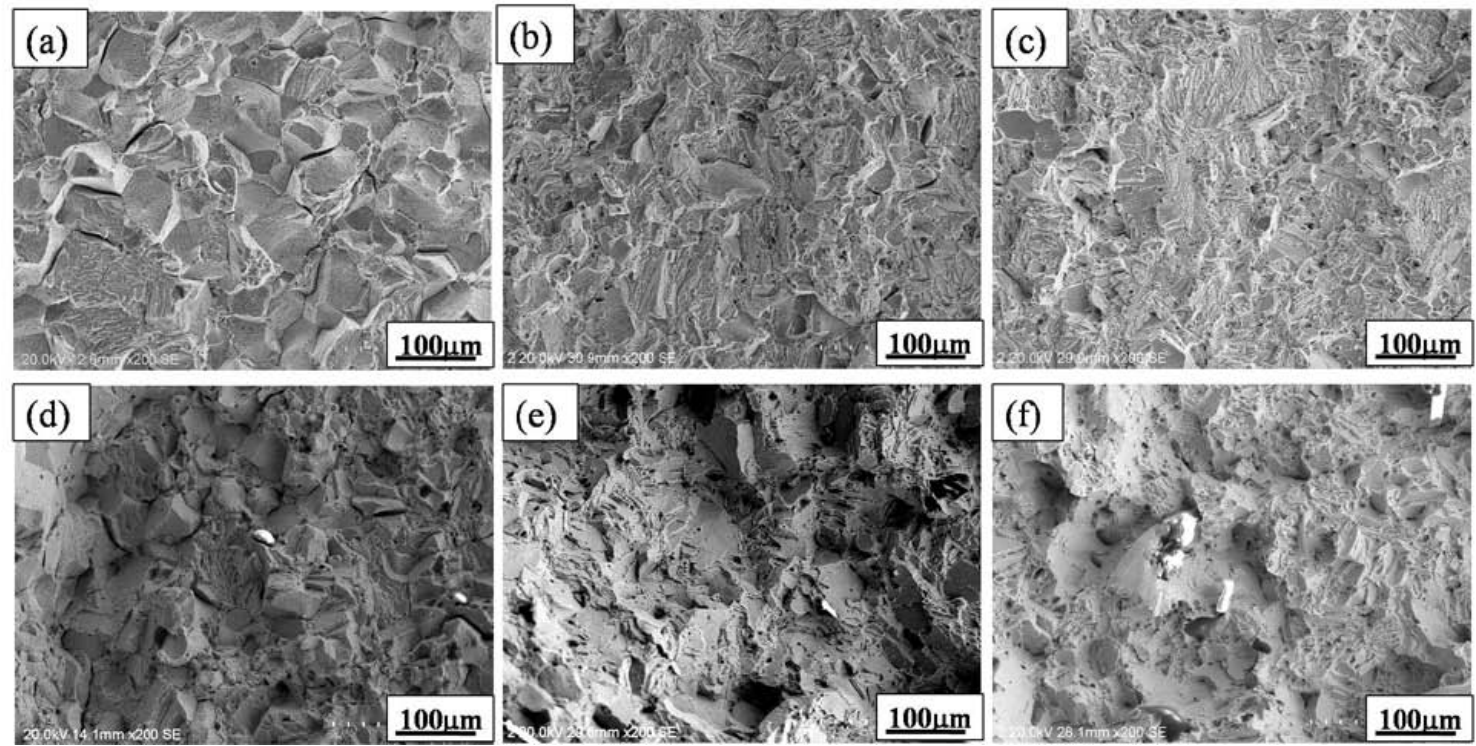

Figure 7 Fracture surfaces of the Alloy1((a)(d)), Alloy2((b)(e)), and Alloy3((c)(f)). (a)(b) and (c) represent the room temperature, (d)(e) and (f) represent the $400^{\circ} \mathrm{C}$. 


\section{Microstructures associated with serrated flow}

\section{Fracture surface}

Fractographic observations and stress-strain curves (Fig.3 and Fig.4) showed that no necking happened before fracture and RT and in the DSA regime. Fracture surfaces of the three alloys with different Co content are shown in Figure 7. The alloy1 showed the transgranular and intergranular fracture at room temperature (Fig.7(a)), and other samples tested at RT and $400^{\circ} \mathrm{C}$ showed the presence of equiaxed dimples, indicating the ductile mode of fracture in both the cases. These observations suggested that the characteristic of fracture in the serrated flow regime did not differ from those in the smooth flow regime.
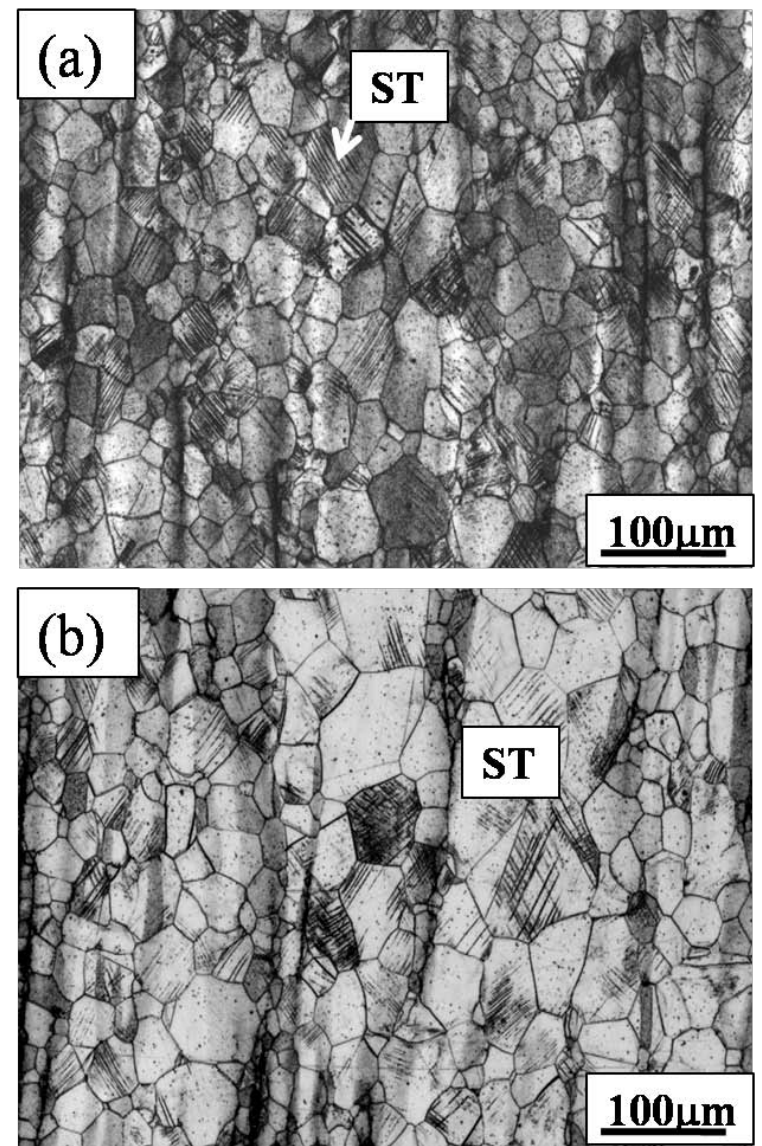

Figure 8 Optical micrographs showing deformation microstructures of Alloy3 tested at (a) normal DSA regime $\left(350^{\circ} \mathrm{C}\right)$ and (b) inverse DSA regime $\left(450^{\circ} \mathrm{C}\right)$. The strain rate employed is $3 \times 10^{-4}$ $\mathrm{s}^{-1}$. The stress direction is near vertical. ST means slip trace.

\section{Optical microscopy observation}

Figure 8 provides optical micrographs of the sample's side surface showing traces of basal slip traces formed on the surface of specimens that have been subjected to fracture at different testing temperatures. It was common to observe traces of slip at both $350^{\circ} \mathrm{C}$ and $450^{\circ} \mathrm{C}$, implying that there was no correlation between serrated flow and the operation of dislocation. In addition, the amount of deformation was greater in Fig.8(a) than Fig.8(b). This may be caused by random difference, because the elongations at these conditions were about $15 \%$.

\section{TEM observation}

Figure 9 shows the TEM observation in order to understand the different deformation mechanism between normal and inverse DSA. Here, we only observed the Alloy3 with low stacking fault energy, due to the time limit. High density of dislocations was formed in the $\gamma$ matrix and it was difficult to shear the secondary $\gamma^{\prime}$ precipitate in the normal DSA regime (Fig.9(a)). In contrast, SFs were present in the inverse DSA regime, and $\gamma$ ' precipitates were sheared by nearly continuous SFs, as shown in Fig.9(b). These results were consistent with our previous study [8].
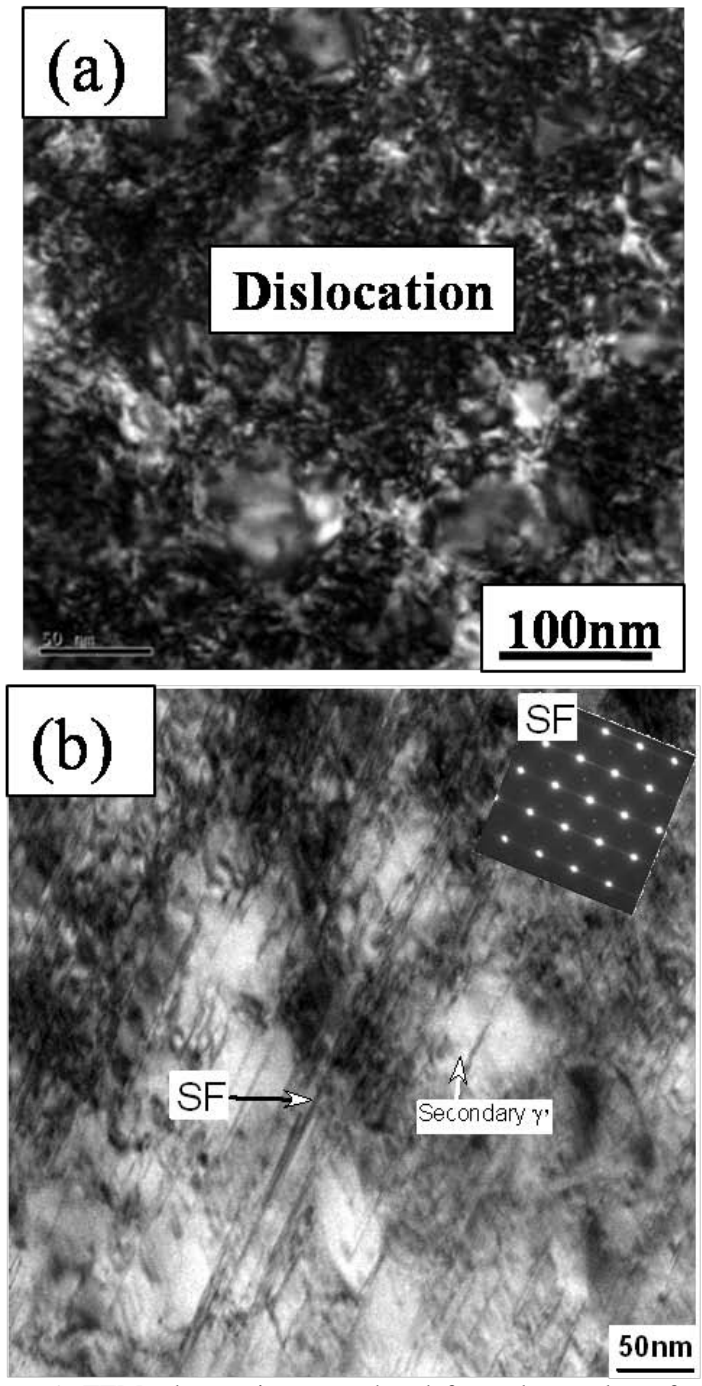

Figure 9 TEM observations on the deformed samples of the Alloy3 tested at (a) $350^{\circ} \mathrm{C}$ and $3 \times 10^{-4} \mathrm{~s}^{-1}$, showing the high density of dislocations occurred in normal DSA regime, and (b) $450^{\circ} \mathrm{C}$ and $3 \times 10^{-4} \mathrm{~s}^{-1}$, showing the $\gamma^{\prime}$ precipitates were sheared by the continuous SFs in the inverse DSA regime. 


\section{Discussion}

It was shown that the SFE of the alloys decreased continuously with increasing Co contents from $5 \mathrm{wt} \%$ to $23 \mathrm{wt} \%$ Co (Table I), and that the serrated flow was also affected by Co content in the alloys. That is, the starting temperature for serration increased from $200^{\circ} \mathrm{C}$ in Alloy 1 to $300^{\circ} \mathrm{C}$ in Alloy3 with increasing the Co content (Fig.3, Fig.4 and Table IV), implying that the starting temperature for serration was affected by the SFE of the alloys. It was known that the dislocations with Burgers vector of $a / 2<110>$ could easily split into two Shockley partials with a stacking fault between them in the fcc alloy with low SFE [15]. In the Co-Ni alloys with higher Co content [16], the starting temperature for serration was reported to be about $550^{\circ} \mathrm{C}$, which exceeded the temperature ranges for serration in the Ni-base alloys with low SFE. Thus, the improvement in the starting temperature for serration was related to the reduction of SFE of the alloy with Co additions.

In the present study, the true stress-strain curves were serrated at $200-500^{\circ} \mathrm{C}$ in tested alloys (Fig.3 and Fig.4). Similar phenomena are generally explained in the literature to be due to the formation of an atmosphere around dislocations, depending on the measured $\mathrm{Q}$ values. The test regimes have been classified into normal and inverse DSA. A typical value of the activation energy determined by various researchers for the normal DSA is in the range of $40-110 \mathrm{~kJ} / \mathrm{mol}$ [6]. Since this value is very close to that for the diffusion of $\mathrm{C}$ in the $\mathrm{Ni}$ matrix[17], the mechanism for serrated phenomena in the normal DSA regime was attributed to interstitial carbon atoms [2,3]. However, in the inverse DSA regime, the average activation energy is around $200 \mathrm{~kJ} / \mathrm{mol}[7,16]$. Hale et al. [7] have explained the appearance of serrations at high temperature to the diffusion of carbide-forming $\mathrm{Cr}$ solute to dislocations. Hayes [2] attributed the high activation energy to the diffusion of $\mathrm{Nb}$ solute to the dislocations and the heterogeneous formation of $\mathrm{NbC}$, thereby depleting the $\mathrm{C}$ atmospheres. However, no experimental evidence for heterogeneous precipitation of carbides on dislocations has been reported so far. In a recent study, Gopinath [4] calculated the activation energy of $80 \mathrm{~kJ} / \mathrm{mol}$ in U720Li and attributed the inverse DSA to the locking of the mobile dislocation by substitutional alloying elements. Because the present alloys had similar chemical composition to U720Li, the mechanism for the inverse DSA was also related to the locking of the mobile dislocation by substitutional element.

All the tested alloys showed the normal and inverse DSA (Fig.5 and Table IV). The activation energy Q was $40-60 \mathrm{~kJ} / \mathrm{mol}$ in the normal DSA regime and $100-120 \mathrm{KJ} / \mathrm{mol}$ in the inverse regime respectively. These results indicated that the Co had no effects on the DSA type and activation energy. As discussed above, the mechanism for the normal DSA regime was related to the interaction of interstitial $C$ atom with mobile dislocation. Since the three alloys had the same $\mathrm{C}$ content, the $\mathrm{Q}$ region kept the same for all the three alloys. In contrast, the mechanism for the inverse DSA regime was related to the interaction of substitutional element with mobile dislocation. These alloys had the similar $\mathrm{Q}$ value, implying that the Co element was not responsible for the mechanism. Therefore, the mechanism of normal and inverse DSA in the Ni-Co base superalloy was consistent with the previously postulated mechanism for other alloys from the measured $Q$ values.
From the microstructural view, high density of SFs was found not in the normal DSA regime, but in the inverse DSA (Fig.9(b)), probably due to the low stacking energy in Alloy3. So far, the effects of planar defects, such as SFs, on DSA have rarely reported in reference. Thus, there was probably a relation between the high density of stacking fault with the inverse DSA effect in the Ni-Co-base superalloy. Further works are needed to clarify the effect of SFs motion on DSA mechanism, particularly on the inverse DSA.

\section{Summary}

In this paper, the effects of stacking fault energy on DSA in a Ni-base superalloy were investigated and the following results could be drawn:

1. The alloys with different Co content mainly consisted of $\gamma$ matrix, $\gamma^{\prime}$ and small amount of carbides. Adding Co had little effect on the phase constituents, but the SFE of $\gamma$ matrix decreased continuously with increasing Co content.

2. All the alloys exhibited serrated flow during tensile deformation due to DSA within an intermediate temperature range of $200^{\circ} \mathrm{C}-500^{\circ} \mathrm{C}$. The starting temperature for serration increased from $200^{\circ} \mathrm{C}$ in Alloy 1 to $300^{\circ} \mathrm{C}$ in Alloy 3 with increasing the Co content from $5 \mathrm{wt} \%$ to $23 \mathrm{wt} \%$, showing that the starting temperature for serration was affected by the SFE of the alloys.

3. In the serrated flow regime, all the alloys clearly exhibited the normal and inverse DSA behaviors. The tensile properties such as yield stress, ultimate tensile strength and fracture features in DSA regime were not influenced by temperatures and strain rates.

4. A relation between high density of SF and the inverse DSA effect was found in the Ni base superalloys with low stacking fault energy (SFE).

\section{Acknowledgements}

This work was partly supported by " Hundreds of Talents Project", National Basic Research Program (973 Program) of China under grant No. 2010CB631200 (2010CB631206) and National Natural Science Foundation of China (NSFC) under Grant Nos. 51171179 and 51128101.

\section{References}

1. P. Rodriquez, "Serrated plastic flow", Bull.Mater. Sci. India 6 (1984) 653-663.

2. R.W.Hayes, and W.C.Hayes, "On the mechanism of delayed discontinuous plastic flow in an age-hardened nickel alloy", Acta Metal. 30 (1982) 1295-1301.

3. R.W.Hayes, "On a proposed theory for the disappearance of serrated flow in f.c.c. Ni alloys”, Acta Metal. 3(1)(1983)365- 371.

4. K.Gopinath, A.K.Gogia, S.V.Kamat and U.Ramamurty, "Dynamic strain aging in Ni-Based superalloy U720Li", Acta. mater. 57(2009) 1243-1253.

5. W. Chen, and M.C. Chaturvedi, "On the mechanism of serrated deformation in aged Inconel 718”,Mater. Sci. Eng. A229 (1997) 163-168.

6. S.A.Nalawade, M.Sundararaman, R.Kishore and J.G.Shah, "The influence of ageing on the serrated yielding phenomena in a nickel base superalloy”, Scripta.mater. 59(2008) 991-994.

7. C.L.Hale, W.S.Rollings and M.L.Weaver, "Activation energy calculations for discontinuous yielding in Inconel 718SPF", Mater. Sci\&Eng.A. 300(2001)153-164. 
8. C.Y.Cui, Y.F.Gu, Y.Yuan and H.Harada, "Dynamic strain aging in a new Ni-Co base superalloy”, Scripta.mater. 64(2011) 502-505.

9. C.Y.Cui, T.Jin and X.F.Sun, "Effects of heat treatments on the serrated flow in a Ni-Co-Cr base superalloy", J.Mater.Sci, 46 (2011) 5546-5552.

10. J.A.Lee, "Effects of the density of states on the stacking fault energy and hydrogen embrittlement of transition metals and alloys”, in Proceedings of the 2008 International Hydrogen Conference (Grand Teton Natl. Park, WY. September 7-10, 2008), p.678.

11. X.L.Nie, R.H.Wang, Y.Y.Ye, Y.M.Zhou, and D.S.Wang, "Calculations of stacking fault energy for fcc metals and their alloys base on an improved embedded-atom method", Solid State Commun, 96(1995)729.

12.Y.Yuan, Y.F.Gu, C.Y.Cui, T.Osada, Z.H.Zhong, T.Tetsui, T.Yokokawa and H.Harada, "Influence of Co content on stacking fault energy in Ni-Co base disk superalloys”, J.Mater.Res, 26(22) (2011)2833-2837.

13. M.P.Jackson, and R.C.Reed, "Heat treatment of UDIMET 720Li: the effect of microstructure on properties”, Mater.Sci\& Eng.A, 259(1)(1999)85-97.

14. P.G.McCormick, "Model for Portevin-Le Chatelier effect in substitutional alloys", Acta metal, 20(1972) 351.

15. P.Li,S.X.Li, Z. G.Wang, and Z.F.Zhang, "Fundamental factors on formation mechanism of dislocation arrangements in cyclically deformed fcc single crystals", Prog.Mater.Sci, 56 (2011) 328-377.

16. A.Chiba, X.G.Li and M.S.Kim, "High work-hardening rate and deformation twinning of Co-Ni-based superalloy at elevated temperatures”, Philo.Mag.A,79(7)(1999)1533-1554.

17.W.F.Gale, T.C.Totemeier, editors. Smithells metals reference book. London: Butterworth-Heinemann; 2004.pp.3-25. 